\title{
FORMULASI SEDIAAN KRIM EKSTRAK ETANOL DAUN KALIANDRA (Calliandra surinamensis) DAN UJI AKTIVITAS ANTIBAKTERINYA TERHADAP BAKTERI Staphylococcus aureus
}

\author{
Gichella Carolina Junitha Somba ${ }^{1)}$, Hosea Jaya Edy ${ }^{1)}$, Jainer Pasca Siampa ${ }^{1)}$ \\ ${ }^{1)}$ Program Studi Farmasi FMIPA UNSRAT Manado, 95115
}

\begin{abstract}
This study aims to test the antibacterial effectiveness of ethanolic extract of Kaliandra leaf cream and evaluate the preparations using parameters of physical properties, physical stability, and sterility. Kaliandra leaf (Calliandra surinamensis) contains compounds such as flavonoid, saponins and tannins that can inhibit the growth of bacteria. This research uses laboratory experimental methods. Cream preparation formula is made with variations in the concentration of ethanol extract of Kaliandra leaves 2\%, 3\%, 4\%, 5\%, 6\%. Kaliandra leaf extract was obtained by maceration using 96\% ethanol solvent. The study of antibacterial test of ethanol extract of Kaliandra leaf extract using the method of Staphylococcus aures produced inhibitory power of $5.09 \pm 0.88 \mathrm{~mm}$ at a concentration of $6 \%$. The physical evaluation of the cream preparation includes organoleptic examination (odor, color, shape), homogeneity, pH testing, adhesion, dispersion, cycling test. All tests are carried out before and after the cycling test. The results obtained before and after the cycling test showed that the cream preparations met organoleptic requirements, homogeneity, cream pH 6.07 (4.5-6.5), cream adhesion 4.59 seconds (<4 seconds), cream dispersion $6.19 \mathrm{~cm}(5-7 \mathrm{~cm})$. Cream sterility testing shows that the cream is sterile. It can be concluded that the ethanol extract of Kaliandra leaves cream meets the physical test parameters, is stable and has moderate antibacterial activity.
\end{abstract}

Keywords : Kaliandra Leaf(Calliandra surinamensis), Cream, Antibacterial, Staphylococcous aureus.

\section{ABSTRAK}

Penelitian ini bertujuan untuk menguji efektivitas antibakteri sediaan krim ekstrak etanol daun Kaliandra dan mengevaluasi sediaan dengan menggunakan parameter uji sifat fisik, stabilitas fisik, dan sterilitas. Daun Kaliandra (Calliandra surinamensis) merupakan tanaman yang mengandung senyawa flavonoid, saponin dan tannin yang mampu menghambat pertumbuhan bakteri. Penelitian ini menggunakan metode eksperimental laboratorium, Formula sediaan krim dibuat dengan variasi konsentrasi ekstrak etanol daun Kaliandra 2\%,3\%,4\%, 5\%, 6\%. Ekstrak daun Kaliandra diperoleh dengan cara maserasi menggunakan pelarut etanol 96\%. Penelitian uji antibakteri sediaan krim esktrak etanol daun Kaliandra menggunakan metode sumuran pada bakteri Staphylococcus aures menghasilkan

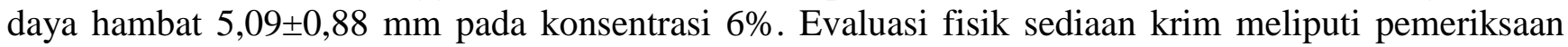
organoleptis (bau, warna, bentuk), homogenitas, pengujian $\mathrm{pH}$, daya lekat, daya sebar, uji cycling test. Semua pengujian dilakukan sebelum dan sesudah cycling test. Hasil penelitian yang didapat sebelum dan sesudah cycling test menunjukkan bahwa sediaan krim memenuhi persyaratan organoleptis, homogenitas, pH krim 6,07 (4,5-6,5), daya lekat krim 4,59 detik (<4 detik), daya sebar krim 6,19 cm $(5-7 \mathrm{~cm})$. Pengujian sterilitas krim menunjukan bahwa krim steril. Dapat disimpulkan bahwa sediaan krim ekstrak etanol daun Kaliandra memenuhi parameter uji fisik, stabil dan memiliki aktivitas antibakteri yang sedang.

Kata kunci : Daun Kaliandra (Calliandra surinamensis), Krim, Antibakteri, Staphlococcous aureus. 


\section{PENDAHULUAN}

Penyakit infeksi kulit disebabkan oleh bakteri. Ada beberapa bakteri dan jamur patogen yang mampu bereproduksi untuk menginfeksi manusia yaitu Staphylococcus aureus, Streptococcus pyrogens seperti selulit, erisipelas, impetigo, folikulitis, furunkel, karbunkel (bisul) (Leboffe dan Pierre, 2011).

Staphylococcus aureus merupakan flora normal pada kulit manusia. Flora normal adalah sekumpulan mikroorganisme yang hidup pada kulit dan selaput lendir/mukosa manusia yang sehat maupun sakit. Adanya flora normal pada bagian tubuh tidak selalu menguntungkan, dalam kondisi tertentu flora normal dapat menimbulkan penyakit dengan tanda-tanda yang khas, yaitu peradangan, nekrosis dan pembentukan abses yang umumnya bersifat sporadic (Jawetz, dkk., 2005).

Dalam mengobati penyakit infeksi bakteri, masyarakat umumnya menggunakan antibiotik, namun penggunaan antibiotik yang tidak terarah menyebabkan bakteri menjadi resisten. Peningkatan resistensi bakteri terhadap antibiotik memberikan peluang untuk memanfaatkan senyawa bioaktif dari kekayaan hayati (Herawati dan Amelia, 2018). Seiring berjalannya waktu, pengetahuan tentang tumbuhan obat makin berkembang dan kini tanaman obat telah digali manfaatnya, salah satunya adalah Daun Kaliandra (Calliandra surinamensis).

Berdasarkan penelitian Tim Laboratorium INTP (2007) terdapat kandungan tannin $11 \%$. Tannin di dalam daun Kaliandra bekerja dengan cara berikatan dengan dinding sel mikroorganisme dan mampu menghambat pertumbuhan mikroorganisme atau menghambat enzim. Dari hasil penelitian yang dilakukan oleh (Artana, dkk., 2016) menunjukan bahwa ekstrak dari daun Kaliandra dapat menghambat pertumbuhan jamur Aspergilus flavus pada konsentrasi ekstrak 100.000 ppm dengan rata-rata zona hambat sebesar 12,27 $\pm 0,27 \mathrm{~mm}$.

Berdasarkan aktivitas antibakteri yang dimiliki daun Kaliandra, maka perlu dikembangkan suatu sediaan farmasi untuk mempermudah penggunaannya. Salah satu sediaan farmasi yang dapat memudahkan penggunaannya ialah krim.

Krim merupakan sediaan setengah padat yang digunakan untuk kulit dan bertujuan untuk pemakaian luar. Sediaan krim yang dimaksudkan memiliki sifat yang tidak lengket, mudah menyebar rata di permukaan kulit berkhasiat sebagai antibakteri merupakan sediaan yang absorbsi bahan aktifnya dari luar kulit ke posisi bawah kulit tercakup masuk ke dalam aliran darah yang disebut sebagai absorbsi perkutan, membawa bahan obat melalui kulit dan tingkat penembusan obat pada kulit lebih cepat dibandingkan dengan pembawa farmasetika tidak dapat jauh menembus kulit (Ansel, 2008).

\section{METODOLOGI PENELITIAN}

Penelitian ini menggunakan metode penelitian eksperimental laboratorium, dalam melaksanakan eksperimen peneliti menggunakan beberapa seri konsentrasi untuk melihat pengaruh dari beberapa perlakuan.

Alat yang digunakan dalam penelitian ini ialah alat-alat gelas (Iwaki ST Pyrex ${ }^{\circledR}$ ), timbangan digital $\left(\mathrm{AE} \mathrm{Adam}{ }^{\circledR}\right)$, hotplate magnetic stirrer (Nesco $\left.{ }^{\circledR} \mathrm{Lab}\right)$, mikropipet, $\mathrm{pH}$ meter, oven, autoklaf $\left(\mathrm{ALP}^{\circledR}\right)$, inkubator $\left(\right.$ Ecocell $\left.^{\circledR}\right)$, bacteri coloni counter $\left(\right.$ Health $\left.^{\circledR}\right)$, blender $\left(\right.$ Miyako $\left.^{\circledR}\right)$, penggaris berskala, jangka sorong, wadah krim, lemari pendingin, ayakan 60 mesh.

Bahan yang digunakan dalam penelitian ini ialah daun Kaliandra (Calliandra surinamensis), Etanol 96\%, Ekstrak daun Kaliandra, Setil Alkohol, Gliserin, TEA (Triethanolamin), Parafin Cair, Asam Stearat, Aquadest, Nutrien Agar, krim gentamicin, Nacl 0.9\% larutan Mc Farland, Bakteri Staphylococcus aureus, Krim Gentamicin.

\section{Persiapan Sampel}

Daun Kaliandra diambil dari Kelurahan Tara-Tara, Kecamatan Tomohon Utara, kota Tomohon. Daun yang diambil adalah Daun Kaliandra yang masih dalam keadaan yang baik. Daun Kaliandra yang telah diperoleh, dicuci bersih, ditiriskan dan di rajang kemudian di keringkan dengan cara diangin-anginkan 
kurang lebih 5 hari dan dilanjutkan pengeringan di dalam oven dengan suhu $40^{\circ} \mathrm{C}$ hingga kering. Kemudian daun Kaliandra yang telah kering di blender hingga halus.

\section{Ekstrak Sampel}

Proses ekstraksi menggunakan metode maserasi yang dilakukan terhadap $400 \mathrm{~g}$ serbuk menggunakan 1,6 L etanol (1:4) selama 3x24 jam. Filtrat diperoleh melalui penyaringan lalu diuapkan didalam oven sehingga diperoleh ekstrak kental lalu di timbang.

\section{Formulasi sediaan krim}

Pada penelitian ini, Formulasi sediaan krim di buat dengan berbagai variasi konsentrasi, yaitu $2 \%, 3 \%, 4 \%, 5 \%, 6 \%$. Dapat dilihat pada tabel 1.

Tabel 1. Formulasi Sediaan Krim

\begin{tabular}{ccccccc}
\hline No. & Nama Bahan & \multicolumn{5}{c}{ Formula $(\% \mathrm{~b} / \mathrm{v})$} \\
\cline { 3 - 7 } & & $\mathrm{F} 1$ & $\mathrm{~F} 2$ & $\mathrm{~F} 3$ & $\mathrm{~F} 4$ & $\mathrm{~F} 5$ \\
\hline 1. & Ekstrak Daun & 2 & 3 & 4 & 5 & 6 \\
& Kaliandra & & & & & \\
2. & Asam Stearat & 16 & 16 & 16 & 16 & 16 \\
3. & Setil Alkohol & 2 & 2 & 2 & 2 & 2 \\
4. & Gliserin & 8,5 & 8,5 & 8,5 & 8,5 & 8,5 \\
5. & TEA & 7 & 7 & 7 & 7 & 7 \\
6. & Parafin Cair & 10 & 10 & 10 & 10 & 10 \\
7. & Aquadest & ad & ad & ad & ad & ad \\
& & 100 & 100 & 100 & 100 & 100 \\
\hline
\end{tabular}

\section{Pembuatan krim ekstrak daun Kaliandra}

Alat dan bahan disiapkan. Masing-masing bahan ditimbang sesuai dengan perhitungan bahan. Fase minyak dibuat dengan melebur asam stearat, tambahkan parafin cair, tambahkan setil alkohol di atas hot plate, suhu dipertahankan pada suhu $70^{\circ} \mathrm{C}$. Fase air dibuat dengan melebur TEA dan gliserin diatas hot plate hingga meleleh tambahkan air panas diaduk hingga homogen, suhu dipertahankan $70^{\circ} \mathrm{C}$. Krim dibuat dengan cara menambahkan fase minyak ke dalam fase air. Bila suhu krim sudah mencapai suhu $\pm 45^{\circ} \mathrm{C}$, kemudian ditambahkan ekstrak daun Kaliandra yang sudah diencerkan dengan propilenglikol sambil terus diaduk sampai homogen.

\section{Sterilisasi Alat}

Sterilisasi alat dilakukan sebelum semua peralatan digunakan, yaitu dengan cara membungkus semua peralatan dengan aluminium foil kemudian dimasukan dalam Autoklaf pada suhu $121^{\circ} \mathrm{C}$ dengan tekanan 1 atm selama 15 menit. Alat yang tidak tahan panas tinggi disterilisasi dengan alkohol $70 \%$.

\section{Pembuatan Media Agar}

Nutrien Agar (NA) sebanyak 2,8 g dilarutkan dalam $100 \mathrm{~mL}$ aquades menggunakan Erlenmeyer. Selanjutnya media disterilkan dengan autoclave dengan suhu $121^{\circ} \mathrm{C}$ selama 15 menit, kemudian dibiarkan pada suhu ruangan selama \pm 30 menit sampai kemudian media memadat. Media agar ini digunakan untuk inokulasi bakteri, lapisan dasar, dan lapisan kedua.

\section{Pembuatan Standar Kekeruhan Larutan Mac. Farland 0,5}

Larutan $\mathrm{H}_{2} \mathrm{SO}_{4} 1 \%$ sebanyak $9.95 \mathrm{~mL}$ dicampurkan dengan larutan $\mathrm{BaCl}_{2} 2 \mathrm{H}_{2} \mathrm{O}$ $1,175 \%$ sebanyak $0,05 \mathrm{~mL}$ dalam tabung reaksi. Selanjutnya dikocok sampai terbentuk larutan yang keruh. Kekeruhan larutan ini dipakai sebagai standar kekeruhan suspensi bakeri uji.

\section{Pembuatan Suspensi Uji Bakteri}

Bakteri uji pada media agar miring diambil dengan menggunakan kawat ose steril lalu disuspensikan ke dalam tabung yang berisi 10 mL larutan $\mathrm{NaCl} 0,9 \%$ dalam tabung reaksi kemudian dikocok hingga diperoleh larutan yang keruh. Kekeruhan ini dipakai sebagai standar kekeruhan suspensi bakteri uji.

\section{Pembuatan Media Pengujian}

Uji aktivitas antibakteri terhadap sediaan krim dilakukan dengan menggunakan metode difusi agar (difusi kirby dan baeur yang dimodifikasi) dengan cara sumuran dengan 2 lapisan media agar dengan pengerjaan lapisan agar yang pertama dibuat dengan menggunakan masing-masing $15 \mathrm{~mL}$ NA ke dalam 3 cawan petri, selanjutnya dibiarkan memadat. Setelah memadat, pada permukaan lapisan dasar ditanam 7 pecandang yang diatur jaraknya agar daerah pengamatan tidak bertumpu. Suspensi bakteri dicampurkan kedalam pembenihan NA. Kemudian dituangkan $10 \mathrm{~mL}$ NA ke media pembenihan. Lapisan agar yang kedua dibuat dengan menggunakan masing-masing $15 \mathrm{~mL}$ 
NA yang sudah ditambahkan suspensi bakteri ke dalam 3 cawan petri, selanjutnya dibiarkan memadat. Setelah lapisan kedua memadat, pecandang diangkat secara aseptic menggunakan pinset dari masing-masing cawan petri, sehingga terbentuk sumur-sumur yang akan digunakan dalam uji antibakteri.

\section{Uji efektivitas antibakteri}

Pada sumur-sumur yang berbeda dimasukan krim ekstrak daun Kaliandra dengan konsentrasi $2 \%, 3 \%, 4 \%, 5 \%$, dan $6 \%$, kontrol (-) basis krim tanpa ekstrak, kontrol (+) krim gentamicin sebanyak 0,1 g. Kemudian diinkubasi pada suhu $35-37^{\circ} \mathrm{C}$ selama 24 jam. Diameter zona hambat yang terbentuk diukur menggunakan mikrometer untuk menentukan efektivitas antibakteri.

\section{Evaluasi sediaan krim Uji Organoleptik}

Pemeriksaan organoleptis krim dilakukan untuk mengamati stabilitas fisik sediaan terhadap masing-masing krim yang meliputi bentuk, bau, dan warna (Ansel, 2008). Dilakukan sebelum dan sesudah uji stabilitas.

\section{Uji Homogenitas}

Ditimbang 1 gram krim pada bagian atas, tengah, dan bawah kemudian dioleskan pada sekeping kaca transparan. Uji homogenitas dilakukan dengan mengamati warna sediaan dan melihat apakah terdapat bagian-bagian yang tidak tercampur dengan baik dalam krim (Ida dan Noer, 2012). Dilakukan sebelum dan sesudah uji stabilitas.

\section{Uji pH}

Ditimbang 1 gram krim dan diencerkan dengan $10 \mathrm{ml}$ aquades. Kemudian gunakan $\mathrm{pH}-$ meter yang bagian sensornya dan dibaca $\mathrm{pH}$ pada bagian monitor. $\mathrm{pH}$ sediaan yang memenuhi kriteria $\mathrm{pH}$ kulit yaitu dalam interval 4,5 - 6,5 (Tranggono dan Latifa, 2007). Dilakukan sebelum dan sesudah uji stabilitas.

\section{Uji Daya Lekat}

Ditimbang 0,5 gram krim dioleskan pada plat kaca. Kedua plat kaca ditempelkan hingga plat menyatu, diberikan beban seberat 250 gram selama 5 menit setelah itu dilepaskan, lalu diberi beban pelepasan. waktu dicatat sampai kedua plat saling lepas. sesuai persyaratan daya lekat krim yang baik yaitu lebih dari 4 detik (Wasiaatmadja, 1997). Dilakukan sebelum dan sesudah uji stabilitas.

\section{Uji Daya Sebar}

Ditimbang 0,5 gram diletakkan ditengah tengah plat kaca, dan dibiarkan selama 1 menit. Setelah itu diberi penambahan beban setiap 1 menit 50 g hingga 250 g lalu diukur diameter sebarnya untuk melihat pengaruh beban terhadap perubahan diameter sebar. Persyaratan yang baik akan menghasilkan daya sebar sebesar 5-7 cm (Wasiaatmadja, 1997). Dilakukan sebelum dan sesudah uji stabilitas.

\section{Uji Stabilitas}

Pengujian stabilitas pada penelitian ini menggunakan dengan cycling test. Sampel krim disimpan pada suhu $4^{\circ} \mathrm{C}$ selama 24 jam dan suhu $40^{\circ} \mathrm{C}$ selama 24 jam dilakukan sebanyak 6 siklus dan diamati terjadinya perubahan fisik dari krim pengamatan organoleptik, homogenitas, $\mathrm{pH}$, daya lekat, daya sebar (Dewi, 2010).

\section{Uji Sterilitas}

Nutrien Agar (NA) dalam 750 mL aquades, di atas hotplate magnetic stirrer dengan bantuan stirrer. Media NA kemudian dituang ke dalam tabung-tabung reaksi untuk disterilisasi dalam autoklaf $\left(121^{\circ} \mathrm{C}, 1\right.$ atm, 15 menit). Setelah sterilisasi, media NA dituang ke cawan petri dan dibiarkan memadat. Sediaan yang telah selesai dibuat kemudian di-streak dengan ose pada media agar secara zig-zag. Masing-masing petri kemudian dibungkus dengan plastic wrap dan diinkubasi terbalik pada suhu $30-35^{\circ} \mathrm{C}$ selama 24 jam (Divadi dan Yuliani, 2015).

\section{HASIL DAN PEMBAHASAN}

Hasil ekstraksi maserasi 400 gram serbuk daun Kaliandra dengan pelarut etanol $96 \%$ (1:4) diperoleh ekstrak kental sebanyak 36,7 g. Rendemen yang diperoleh $9,17 \%$ b/v. 
Pengujian antibakteri esktrak etanol daun Kaliandra terhadap Staphylococcus aureus dilakukan tiga kali pengulangan pada konsentrasi $2 \%, 3 \%, 4 \%, 5 \%, 6 \%$.

Tabel 2.Hasil Data Pegujian Mikrobiologi Krim Ekstrak Etanol Daun Kaliandra

\begin{tabular}{cc} 
Sampel & Diameter daerah hambatan $(\mathrm{mm})$ \\
\cline { 2 - 2 } $\mathrm{K}(-)$ & Rata-Rata \pm SD \\
$\mathrm{K}(+)$ & $0 \pm 0,00$ \\
FI & $10,27 \pm 1,53$ \\
FII & $2,61 \pm 0,11$ \\
FIII & $2,95 \pm 0,25$ \\
FIV & $3,31 \pm 0,20$ \\
FV & $3,46 \pm 0,27$ \\
& $5,09 \pm 0,88$
\end{tabular}

Keterangan : K(-): Basis krim tanpa ekstrak, $\mathrm{K}(+)$ : Krim Gentamicin, FI: Formulasi sediaan krim ekstrak etanol Daun Kaliandra konsentrasi 2\%, FII: Formulasi sediaan krim ekstrak etanol Daun Kaliandra konsentrasi 3\%, FIII: Formulasi sediaan krim ekstrak etanol Daun Kaliandra konsentrasi 4\%, FIV: Formulasi sediaan krim ekstrak etanol Daun Kaliandra konsentrasi 5\%, FV: Formulasi sediaan krim ekstrak etanol Daun Kaliandra konsentrasi 6\%.

Pengujian ini perlu untuk dilakukan untuk melihat pada konsentrasi yang paling terbesar untuk menghambat pertumbuhan bakteri Staphylococcus aureus, ditandai dengan tidak adanya pertumbuhan bakteri pada media NA. Hasil pengujian yang didapat dengan konsentrasi 2\%,3\%, 4\%, 5\%, 6\% menunjukan aktivitas antibakteri dengan adanya zona hambat disekitar sumuran. Diameter zona hambat disekitar sumuran diukur menggunakan jangka sorong. Krim ekstrak etanol daun Kaliandra konsentrasi $2 \%$ memberikan daya hambat 2,61 mm, 3\% memberikan daya hambat $2,95 \mathrm{~mm}, 4 \%$ memberikan daya hambat 3,31 $\mathrm{mm}, 5 \%$ memberikan daya hambat $3,46 \mathrm{~mm}$, dari hasil ke 4 konsentrasi tersebut dapat dikategorikan memiliki daya hambat yang lemah sedangkan pada konsentrasi 6\% memberikan daya hambat 5,09 $\mathrm{mm}$ dari hasil tersebut dapat dikategorikan memiliki daya hambat yang sedang. kontrol positif memberikn daya hambat $15 \mathrm{~mm}$ dan kontrol negatif tidak memberikan daya hambat karena menghasilkan zona hambat $0 \mathrm{~mm}$. dari hasil tersebut dapat dilihat bahwa krim ekstrak etanol daun Kaliandra dengan konsentrasi 2\%, 3\%, 4\%, 5\%, dan $6 \%$ bisa menghambat pertumbuhan bakteri Staphylococcus aureus dengan menjadikan konsentrasi terbesar yaitu 6\% dikarenakan pada konsentrasi $6 \%$ memiliki daya hambat yang paling besar, dari konsentrasi terbesar itu dilanjutkan untuk evaluasi fisik sediaan.

Pada pengujian organoleptik yang meliputi warna, bau dan bentuk menunjukkan bahwa formulasi krim yang dihasilkan berwarna hijau, memiliki bau khas ekstrak etanol daun Kaliandra dengan bentuk semi padat. Semakin tinggi penambahan konsentrasi ekstrak daun Kaliandra, maka semakin kuat bau yang dihasilkan. Setelah dilakukan penyimpanan di dalam suhu $4^{\circ} \mathrm{C}$ dan $40^{\circ} \mathrm{C}$ tidak terjadi perubahan warna, aroma, dan bentuk pada sediaan krim, ini dapat diartikan bahwa krim ekstrak etanol daun Kaliandra memiliki stabilitas yang baik dalam penyimpanan karena tetap sama pada waktu sebelum penyimpanan dan sesudah penyimpanan.

Pada pengujian homogenitas ini bertujuan untuk melihat dan mengetahui tercampurnya bahan-bahan sediaan krim sehingga tidak terlihat adanya butiran-butiran kasar. Hasil dari pengujian ini menunjukan bahwa krim memiliki susunan yang homogen serta tidak ada butiran kasar. Setelah dilakukan penyimpanan di dalam suhu $4^{\circ} \mathrm{C}$ dan $40^{\circ} \mathrm{C}$ tidak terjadi perubahan pada sediaan krim, ini dapat diartikan bahwa krim ekstrak etanol daun Kaliandra memiliki stabilitas yang baik dalam penyimpanan karena tetap sama pada waktu sebelum penyimpanan dan sesudah penyimpanan.

Pada pengukuran $\mathrm{pH}$ pada krim ekstrak etanol daun Kaliandra untuk mengetahui kadar asam dan basa dari sediaan krim dan juga untuk melihat keamanan sediaan krim agar tidak mengiritasi kulit ketika diaplikasikan. Hasil dari pengukuran $\mathrm{pH}$ dari krim sebelum dan sesudah penyimpanan dalam suhu $4^{\circ} \mathrm{C}$ dan $40^{\circ} \mathrm{C} 6$ siklus didapatkan nilai $\mathrm{pH}$ rata-rata 6,07 yang menunjukan bahwa $\mathrm{pH}$ dari sediaan krim ekstrak etanol daun Kaliandra ini tidak mengiritasi kulit dikarenakan nilai $\mathrm{pH}$ yang ada sesuai persyaratan yaitu 4,5 - 6,5 sehingga krim ini aman digunakan pada kulit (Tranggono dan Latifa,2007).

Pada pengujian daya lekat dilakukan untuk mengukur kemampuan krim untuk melekat pada saat diaplikasikan pada kulit, hasil dari pengujian daya lekat dari krim sebelum dan sesudah penyimpanan dalam suhu $4^{\circ} \mathrm{C}$ dan 
$40^{\circ} \mathrm{C}$ didapat rata-rata 4,59 detik, sesuai persyaratan daya lekat krim yang baik yaitu lebih dari 4 detik (Wasiaatmadja, 1997) menunjukkan bahwa krim ekstrak etanol daun Kaliandra memiliki daya lekat yang baik, karena semakin lama krim melekat pada kulit maka semakin banyak zat aktif yang diabsorbsi dan krim akan memberikan efek terapi yang lebih optimal.

Pada pengujian daya sebar dilakukan untuk melihat kemampuan menyebar sediaan krim pada permukaan kulit pada saat pemakaian, hasil dari pengujian daya sebar dari krim sebelum dan sesudah penyimpanan dalam suhu $4^{\circ} \mathrm{C}$ dan $40^{\circ} \mathrm{C}$ didapat rata-rata $6,19 \mathrm{~cm}$, sesuai dengan persyaratan yang baik akan menghasilkan daya sebar sebesar 5-7 cm (Wasiaatmadja, 1997) menunjukkan bahwa krim ekstrak etanol daun Kaliandra memiliki daya sebar yang baik. Daya sebar yang baik menyebabkan kontak antara obat dengan kulit menjadi luas, sehingga absorpsi obat ke kulit berlangsung cepat.

Uji stabilitas dilakukan dengan cara cycling test, sebanyak 6 siklus selama 12 hari. Sediaan krim disimpan pertama pada suhu $\pm 4^{\circ} \mathrm{C}$ selama 24 jam dan dilanjutkan pada suhu $\pm 40^{\circ} \mathrm{C}$ selama 24 jam, proses ini dihitung 1 siklus (Dewi, 2010).

Pada pengujian sterilitas dilakukan untuk mengetahui keadaan sediaan krim bebas dari mikroba. untuk melakukan uji sterilisasi yang terpenting adalah keadaan harus steril, dan setelah diinkubasi selama 24 jam didapat hasil tidak adanya mikroorganisme. yang menunjukkan bahwa sediaan krim ekstrak etanol daun Kaliandra steril.

\section{KESIMPULAN}

Berdasarkan hasil penelitian dapat disimpulkan bahwa sediaan krim ekstrak etanol daun Kaliandra dapat memberikan efek antibakteri terhadap bakteri Staphylococcus aureus dengan diameter rata-ratanya pada konsentrasi 2\% (2,61 mm), 3\% (2,95 mm), 4\% $(3,31 \mathrm{~mm}), 5 \%(3,46 \mathrm{~mm}), 6 \%(5,09 \mathrm{~mm})$. Berdasarkan uji aktivitas antibakteri terhadap bakteri Staphylococcus aureus diperoleh bahwa krim dengan konsentrasi 6\% memberikan penghambatan paling besar. Ekstrak etanol daun Kaliandra dapat diformulasikan menjadi sediaan krim dengan konsentrasi 2\%, 3\%, 4\%, $5 \%, 6 \%$ dan telah memenuhi syarat parameter uji yaitu pengujian organoleptik, homogenitas, $\mathrm{pH}$, daya sebar, daya lekat, dan stabilitas.

\section{SARAN}

Disarankan kepada penelitian selanjutnya untuk perlu dilakukan evaluasi fisik yang belum dilakukan dalam penelitian ini yaitu uji viskositas, dan uji Iritasi.

\section{DAFTAR PUSTAKA}

Ansel, H.C, 2008. Pengantar Bentuk Sediaan Farmasi, edisi IV, Ahli bahasa Ibrahim, F. Jakarta:UI Press.

Artana, I.G., Darmayasa, G., Proborini, M.W. 2016. Daya Hambat Ekstrak Kasar Daun Kaliandra (Calliandra calothyrsus Meissn.) Terhadap Jamur Kontaminan Pada Pakan Konsentrat Ayam Ras Pedaging. Jurnal Simbosis IV. (2):31-38.

Dewi R.K. 2010. Optimasi Formulasi Mikroemulsi Sediaan Hormon Testosteron

Undekanoa.Jakarta:Universitas Negeri Islam Negeri Syarif Hidayatullah.

Divadi, A., Yuliani, S.H. 2015. Pembuatan dan Uji Aktivitas Sediaan Gel Scarless Wound dengan Ekstrak Binahong dan Zat Aktif Piroxicam. Jurnal Farmasi Sains dan Komunitas. 12(2):41-47.

Herawati E., Amelia., T. R. N. 2018. Potensi Bahan Herbal Ekstrak Etanol Daun Mengkudu Asal Desa Wajar Lor. Tulungagung, Jawa Timur. Terhadap Bakteri Penyebab Jerawat. Jurnal Kesehatan. 2(2).

Ida, N., Noer, S.F. 2012. Uji Stabilitas Fisik Gel Ekstrak Lidah Buaya (Aloe Vera L.). Majalah Farmasi dan Farmakologi. 16 (2): 79-84 
Jawetz, E., Melnick, J. L., Adelberg, E. A. 2005. Medical Microbiology. McGraw-Hill, USA: 227 - 276.

Leboffe, MJ., Pierre BE. 2011. A Photographic Atlas for the Microbiology Laboratory. Morton Publishing Company.

Tranggono, R.I., Latifah, F. 2007. Buku Pegangan Ilmu Pengetahuan Kosmetik. Jakarta: Gramedia Pustaka Utama. Halaman 33-36.

Wasitaatmadja, S.M. 1997. Penuntun Ilmu Kosmetik Medik. Jakarta: Penerbit Universitas Indonesia. Hal. 3,5859.62-rotsheki63. 111-112. 